\title{
Equipment for microbiology
}

\author{
This week's selection of new products covers all those that would be used in a \\ microbiology laboratory - from reagents to immunoassay kits.
}

\section{Biologicals}

- Endothelial cell growth supplement (ECGS) is now being supplied by Stratech Scientific. ECGS has been shown to replace feeder cell layers in clonal growth of hybridoma and other cell types. It shows consistency in growth-promoting activity, simplifies culture maintenance and is free from detectable bacteria, fungi and mycoplasma. It is supplied in a lyophilized form which is stable for $2 \mathrm{yr}$ at $4^{\circ} \mathrm{C}$. One vial, containing $15 \mathrm{mg}$, will supplement up to $300 \mathrm{ml}$ of medium.

Circle No. 100 on Reader Service Card.

- Advanced Laboratory Techniques has now added a number of fluorescein (FTC) labelled compounds to its reagent range. These compounds are immunoreactive and intended for use in immunoassay systems. Included in the FTC-labelled range are: amikacin, carbamazepine, digoxin, human placental lactogen, phenobarbital, phenytoin, L-thyroxine and tobramycin. Most of these compounds may be conjugated to various alternative fluorescent labels.

Circle No.101 on Reader Service Card.

- Amersham has added six new restriction endonucleases and one new modifying enzyme to its range of restriction and modifying enzymes. The additions are: $A c c$ II (isolated from Acinetobacter calcoaceticus); $A v a$ I (isolated from the blue green alga Anabaena variabilis); $A v a$ II (isolated from the blue green alga Anabaena variabilis); Dra I (isolated from Deinococcus radiophilus); Eco RV (isolated from Escherichia coli J62 pLG74) and Sac I (isolated from Streptomyces achromogenes). The modifying enzyme is DNA polymerase I from $E$. coli.

Circle No. 102 on Reader Service Card.

Anglian Biotechnology has asked us to make an addition to our report on avian myeloblastosis virus (AMV) reverse transcriptase (see Nature 307, 196). They would like us to point out that the product is manufactured using a technique pioneered by the president of Molecular Genetic Resources, Dr G.E. Houts, and that any queries involving AMV reverse transcriptase should be directed to Molecular Genetic Resources Inc., 6201 Johns Road, Suite 8, Tampa, Florida 33614, USA.
- A range of specific protein rich media is now available from Advanced Laboratory Techniques. The media are suitable for the preparation of serum standards for immunoassay or as a source material for the preparation of protein. The following are immediately available: C-reactive protein (CRP), liver ferritin, placental lactogen (PL) and thyroxine-binding globulin (TBG). All the media are supplied freeze-dried and sold as weight of specific protein. Small samples are available for evaluation.

Circle No.103 on Reader Service Card.

- Two new mounting media, hydramount and dimethyl hydantoin formaldehyde resin, have been added to the BDH Gurr range of stains and microscopy materials. Hydramount is a fast-drying aqueous mounting medium which has adhesive properties when set so that the problems of specimen damage resulting from movements of the coverslip are minimized. Hydramount is suitable for botanical and zoological applications. It has a refractive index of 14668 and a viscosity of $4.71 \mathrm{cP}$ at $20^{\circ} \mathrm{C}$. It is designed for use in microentomology or in the preparation of aquatic micro-invertebrates. Dimethyl hydantoin formaldehyde resin (DMHF) is a water-soluble resin for mounting whole or dissected entomological material. It is designed for use in preparing taxonomic specimens for reference collections. Circle No. 104 on Reader Service Card.

- An improved version of the microbore valve has been introduced by Rheodyne. The new model features $0.2,05$ and $1 \mu \mathrm{l}$ chambers, a $0.13 \mathrm{~mm}$ diameter outlet passage and a built-in syringe needle part with $0.3 \mu \mathrm{l}$ hold-up volume. The previous microbore valves $(7413,7410)$ are still available, but the 7520 is designed to replace them in areas of microbore HPLC where sample size is critical.

Circle No. 105 on Reader Service Card.

Colony stimulating factor and human interleukin 2 are now being produced by Genzyme Koch-Light. Colony stimulating factor (mouse), colony stimulating factor (human) and interleukin 2 (human) can all be supplied. The new lymphokines add to Genzyme's existing range of research biologicals - interleukin 1 (mouse), nerve growth factor (human) and collagen II (chicken).

Circle No. 106 on Reader Service Card.
- The new hand-held UVX Radiometer from UVP has three interchangeable UV sensors. Each sensor has a 36-inch electrically-shielded cable enabling accurate readings from inaccessible locations. Designed for general use within UV-A, UV-B and UV-C wave bands, the sensors come equipped with filters to reduce the solarization characteristically associated with $254 \mathrm{~nm}$ UV sensors. The UVX Radiometer features direct digital readout, automatic test circuitry and a read-hold switch.

Circle No. 107 on Reader Service Card.

- RNasin is now available from Anglian Biotechnology. RNasin is purified by Promega Biotec and can be used in in vitro translation systems using rabbit reticulocyte lysate and in cDNA work using avian myeloblastosis virus reverse transcriptase.

Circle No. 108 on Reader Service Card.

- Two new endoglycosidases are available from Boehringer Mannheim Biochemicals for use in structural studies of glycopeptides and in the removal of sugars from glycoproteins. These glycosidases show very different specificities although both should be used in studies where specific cleavage of glycopeptides or glycoproteins is desired. Endoglycosidase D is specific for the digestion of complex sugars, while endoglycosidase $\mathrm{H}$ is useful for the digestion of high-mannose chains.

Circle No. 109 on Reader Service Card.

- Beckman has announced an addition to its range of Ready-Solv scintillation counting cocktails. The new CP extended clear-phase cocktails solubilize aqueous samples for counting. The cocktails hold up to $33 \%$ of most aqueous samples as a continuous clear liquid emulsion from neat to maximum capacity with no two-phase breaks. It will count the standard sample size of $1 \mathrm{ml}$ in miniature counting vials. It can also be used for the elution of samples in filter counting techniques and for high protein content samples. Ready-Solv CP can be used in any liquid scintillation counter.

Circle No. 110 on Reader Service Card.

These notes are based on information provided by the manufacturers. For further details circle the appropriate numbers on the Reader Service Card bound inside the journal. 


\section{General laboratory equipment}

-The MSJ-T series of fermentors from Bioengineering Associates automates the production of large batches of plant or animal cell cultures. The fermentors are designed for use with cell suspensions or microcarrier beads. Models are available in vessel sizes of $10,20,30,40,50,70$ and 90 litres. The system is controlled by the microprocessor-based Bioprocessor which automates control of $p \mathrm{H}$, dissolved oxygen and temperature. It also runs steam sterilization of the vessel and the medium. Twelve analog and eight digital input ports are available. A computer can be added via the RS232 serial port or the optional IEE-488 interface bus. In addition to the MSJ series, Bioengineering Associates can supply the MD series of bench top fermentors which are offered in five vessel sizes from 1.2 to 10 litres.

Circle No.111 on Reader Service Card.

- Four new thermostatic water baths are available from PolyScience. The units feature a durable polypropylene tray equipped with a heater, circulating pump and a temperature control circuit. The operating range is from ambient to $50^{\circ} \mathrm{C}$ with a control accuracy of $\pm 0.1^{\circ} \mathrm{C}$. These baths are useful in chemistry, biology and photographic laboratories as well as blood bank applications

Circle No.112 on Reader Service Card.

- AMS (Analytical Measuring Systems) has announced the release of a new image analyser to augment its existing system III and VIDS ranges. Called 40-10, the instrument is specifically designed for routine laboratory use. Applications include fluorescent bacteria counting, colony counting, area fraction measurements, diffusion zone area measurements, porosity and cell counting. The system is microprocessor-controlled and includes a built-in printer. The detector is digital, giving 256 grey level set tings, and there is an automatic detection system.

Circle No.113 on Reader Service Card.

- Hybritech has released the GammaPhoton system for isotopic immunoassays. The solid state 24-wcll counter allows sample throughput of 500 tubes per hour, and provides for automated data reduction using a Hewlett-Packard model 87XM computer. The instrument offers data reduction software which gives data reduction of Hybritech's immission rate measuring apparatus format solid-phase monoclonal antibody-based Tandem-R immunometric assays. Gamma-Photon also includes data reduction routines for conventional competitive-binding radioimmunoassays, and for screening assays including hepatitis tests and pregnancy tests.

Circle No. 114 on Reader Service Card.
- The Titer-Pak from Robbins Scientific consists of a plastic box with telescoping cover. This contains a removable 96 -hole rack which is pre-loaded with pipette tips. It is designed for use with multi-nozzle and standard pipettors. The complete TiterPak is disposable and is made of auto. clavable polypropylene. It is also available sterilized by radiation.

Circle No.115 on Reader Service Card.

- A three-dimensional hydraulic microdrive has been introduced by Medical Systems. The MO-103 is small and features a driving actuator which is remotely located from the headstage. Axes $x, y$ and $z$ can be driven smoothly through a cubic centimeter without zigzagging or limping. Control knobs are graduated in steps of 2 $\mu \mathrm{m}$.

Circle No.116 on Reader Service Card.

- The new Harris Lo Temp 16-V upright freezer has a capacity of 16 cubic feet divided into five chambers. Each chamber is fitted with an insulated, magneticallysealed sub-door. The freezer is designed for life sciences, pharmaceutical and blood applications and comes in three models: $-40,-70$, or $-85^{\circ} \mathrm{C}$ low temperature point. Standard on all models are casters and a safety handle and options include air or auxiliary water cooling and a standby $\mathrm{CO}$, system.

Circle No.117 on Reader Service Card.

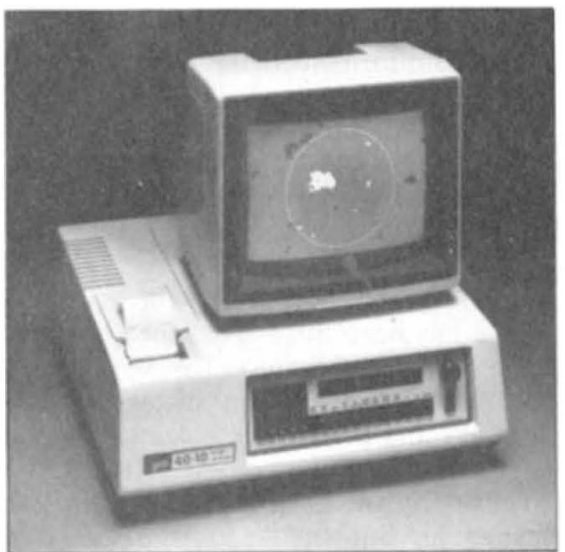

The image analyser from $A M S$
Heraeus has introduced three new types of tissue culture dish to the British market. Flexiperm is a reusable culture vessel made of silicon rubber. Its lower surface adheres to all smooth surfaces to form containers for cell culture. Two containers are available: Flexiperm slide which is designed for use with $76 \times 26 \mathrm{~mm}$ microscope slides and Flexiperm disk which is normally used in conjunction with a Petriperm culture dish. The Quadriperm is a rectangular cell culture dish with four subdivisions in which cells may be cultivated on standard $76 \times 25$ $\mathrm{mm}$ microscope slides.

Circle No.118 on Reader Service Card.

- The Mini Reader II is a manual ELISA reader produced by Dynatech which is coupled to a printer. It incorporates a plugin cartridge programming system. A 96-well micro-ELISA plate can be read by the instrument and the results printed in approximately $2 \mathrm{~min}$. The machine can store a series of readings and will print these readings when required in either a tabular format, a matrix showing positive and negative values or in optical density readings. In addition, the Mini Reader II provides a visual display of readings, wellby-well, with the results shown on the LED display. The machine has an integral keyboard for data entry which permits the user to select blanking on any well of the plate or number of wells in addition to permitting other data entry requirements, such as stored information on print on demand used in conjunction with the program cartridges.

Circle No.119 on Reader Service Card.

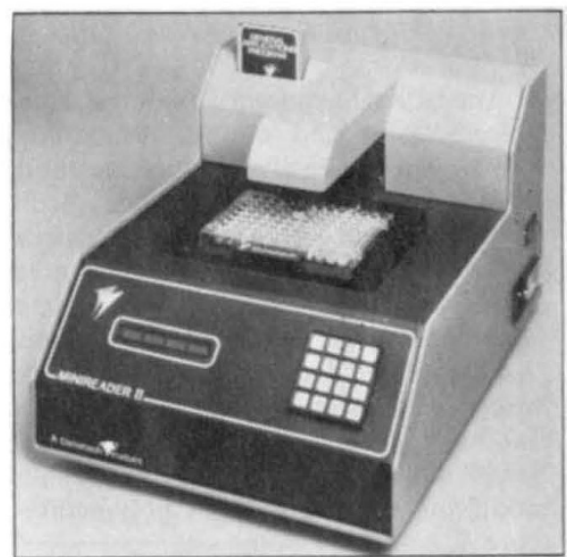

Dynatech's Mini Reader II

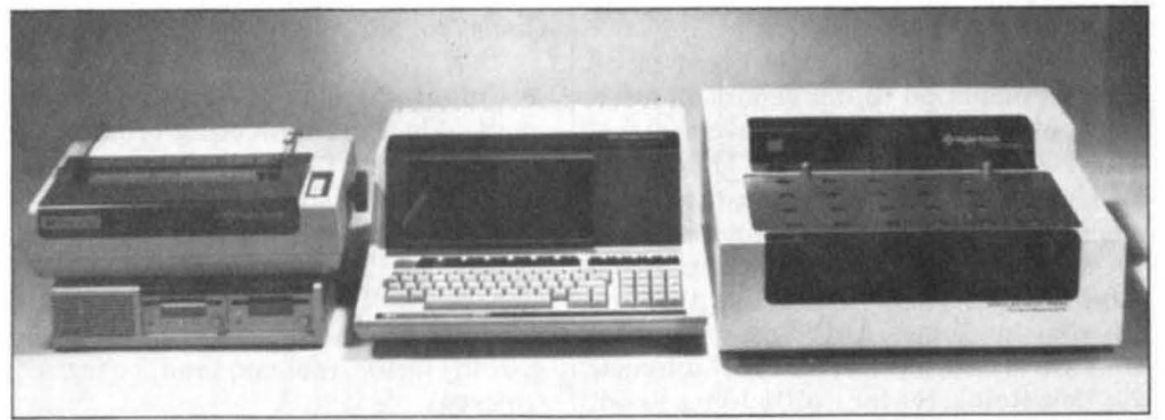

The GammaPhoton system from Hybritech for isotopic immunoassays 


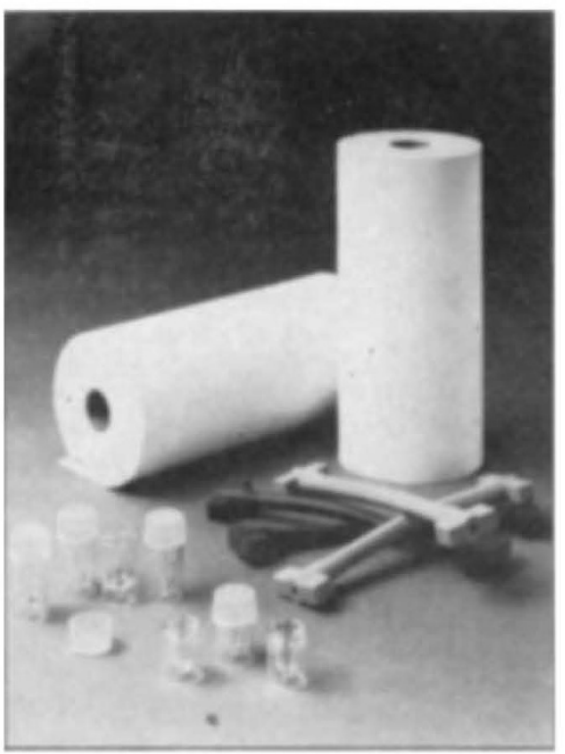

Elkay's pump tubing for Astra

- With the introduction of new Elkay pump tubing for use with Beckman Astra analysers, there is now an alternative single source for plastic consumables for Astra instruments. The silicone tubing is packaged in a press snap lidded polystyrene box.

Circle No.120 on Reader Service Card.

- LDC/Milton Roy has released two new versions of the spectroMonitor, model $1204 \mathrm{~A}$, variable wavelength detector. One version includes a maxN series fluid cell and a digital absorbance display. The standard version of the spectroMonitor III detector includes a 1,000 p.s.i. high pressure fluid cell and an analog absorbance display. The spectroMonitor III baseline drift is $5 \times 10^{-4} \mathrm{~A} \mathrm{~h}^{-1}$ after suitable warm-up. The new versions of the spectroMonitor III detector feature a linear sensitivity range of 0.001-2.0 A full scale.

Circle No.121 on Reader Service Card.

- A new range of pharmaceutical and laboratory autoclaves has been introduced by Edwards High Vacuum. The Edwards Fedegari series FOF autoclaves use the dynamic steam principle of sterilization and have a microcomputer control system dedicated to this sterilization process. There are 24 types of cycle available. Each cycle type must be further programmed by the user with the parameter values required to produce the final programmed cycle. Circle No. 122 on Reader Service Card.

- A new range of UV/visible spectrophotometers, has been introduced by Pye Unicam. The PU8600 series of microprocessor/keypad-operated instruments is headed by two main versions-the PU8600, designed for industrial and teaching applications, and the PU8610 intended for use in the life sciences. A range of new accessories has also been produced.

Circle No. 123 on Reader Service Card.

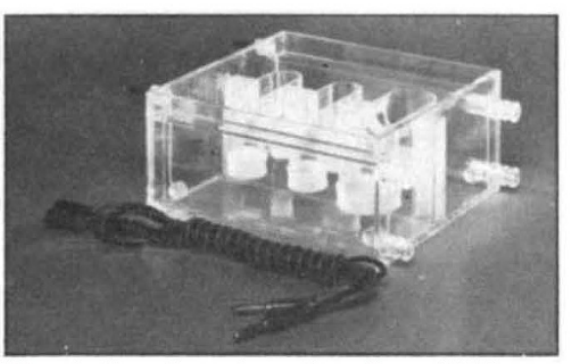

The electrophoresis system from GRI

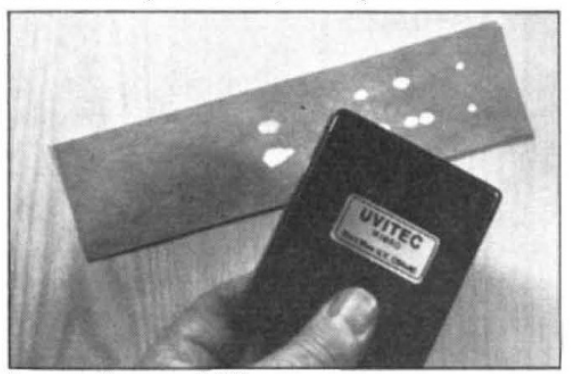

Intersci's new UV source

- Genetic Research Instrumentation has developed an electrophoresis system that is designed for the elution of protein samples from gels and the concentration of macromolecules in solution. The concentrated protein may be harvested either as a concentrate solution or bound to specific activity membranes. The system is based on its sample elution wells. These are two cylindrical wells which are bound to each other by a short bridge. The bottom of each well is covered by a membrane. Proteins migrate from one cup to the other under a constant electrical field of $5 \mathrm{~W}$ within $1 \mathrm{~h}$, either as a solution or bound to the membrane. Up to three samples may be processed simultaneously and two sizes of sample wells are available. The chamber is water-cooled and supplied complete with three sample wells, blank spacers, safety lid and input leads.

Circle No.124 on Reader Service Card.

- Intersci has introduced a small but powerful UV source that is suitable for examining thin layer chromatography plates. The Uvitec Micro is available in short wave $(254 \mathrm{~nm})$ and long wave (365 $\mathrm{nm}$ ) versions and comes complete with batteries and viewing box.

Circle No.125 on Reader Service Card.

- Two new Tissue-Tek vacuum infiltration processors are available from Miles Laboratories. These are microprocessorcontrolled flow-through tissue processors that automatically perform the tasks of fixation, dehydration, clearing and paraffin-impregnation of tissue. The specimens are safely inside a completely enclosed retort during processing. The processors are available in new 100- and 200 -specimen capacity models as well as the original 300-specimen size. They incorporate a control pad which enables the operator to prepare and store up to 10 different processing programs.

Circle No.126 on Reader Service Card.
Coulter Electronics has introduced a new multi-parameter discrete chemistry analyser, Dacos. It can analyse any sample, at any time, with a throughput of 450 tests per hour, carrying out single tests, profiles and statistics. It houses a multi-wavelength optical bench, which rotates around a ring of reaction cuvettes to provide continuous absorbance readings at up to eight wavelengths every $8 \mathrm{~s}$. Dacos uses low sample and reagent volumes with a minimum reaction volume of $120 \mu \mathrm{l}$. It uses reusable reaction cuvettes to keep consumable costs down. One or two reagents may be added and both sample and reagent blanks are taken during the analysis.

Circle No.127 on Reader Service Card.

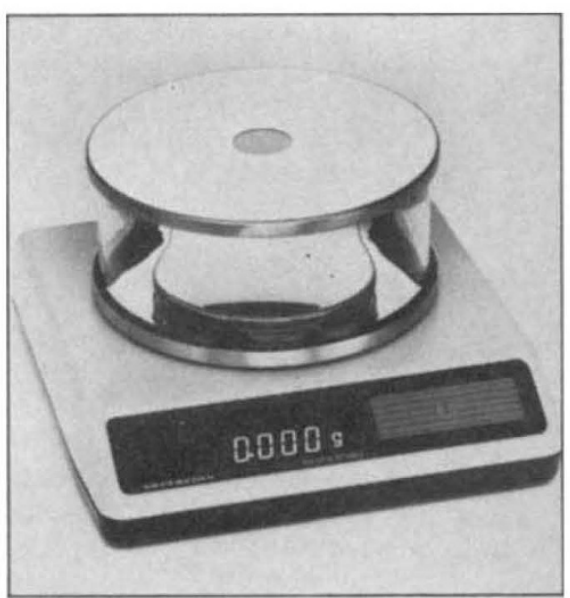

The 1419 balance from Sartorius

Brinkman Instruments has introduced the Sartorius series 1400 milligram balances. The series includes the model 1405 MP8 (220-g capacity, 0.001-g read ability) and the dual-range models 1412 MP8 and 1419 MP8 (30 to 300-g and 60 to 600 -g capacities, respectively, and 0.001 and $0.01 \mathrm{-g}$ readability). The quad-range model 1475 MP8 (420-g capacity) features a fine reading of $0.001 \mathrm{~g}$ which can be activated anywhere within the weighing range by pushing the tare button. Additional readabilities of $0.002,0.005$ and $0.01 \mathrm{~g}$ are automatically displayed at predetermined levels. Additional features include display control of the last digit (always on, always off, or automatically controlled), auto-adjustable display update speed, adjustable digital filter, seven-segment digital display with stabilized readout indicator, automatic electronic calibration and full-range electronic tare. All models come with a stainless steel and glass draft shield.

Circle No.128 on Reader Service Card.

- The new Elkay XLDG macropipettor with digital capacity selection dispenses volumes from 1 to $5 \mathrm{ml}$ with adjustable 500 $\mu$ increments to within $\pm 0.4 \%$ reproducibility. It also has a hexagonal body, feather touch plunger action, positive click-stop, digital capacity adjustment and colourcoding to ensure correct tip usage.

Circle No. 129 on Reader Service Card. 


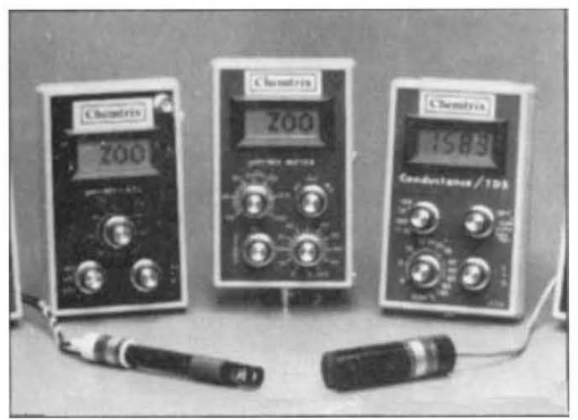

The $\mathrm{pH}$ meters from Chemtrix

- Wheaton Instruments has introduced the Wheaton Unispense/Omni-Pette, an automatic liquid delivery system for aliquoting as well as aspirating. A feature of the system is the Omni-Pette remote control dispensing head which allows fluids to be delivered at some distance from the pump. The Wheaton Unispense/ Omni-Pette will feed, wash and innoculate cells in 90 and 24-well microtest plates when the appropriate microtest manifold is attached to the Omni-Pette. The Wheaton Unispense /Omni-Pette is suited to delivering small volumes of fluid in the 0.1 to $20 \mathrm{ml}$ range. The system is controlled manually by a push button, foot switch or by the flush-mount switch. When programmed in the automatic mode, the Unispense/Omni-Pette will cycle at regular intervals which can also be programmed for $0.5-5 \mathrm{~s}$ delay intervals between cycles. A five-digit LED display records the number of doses dispensed, while a cycle alert signals the end of each dispense cycle. Circle No.130 on Reader Service Card.

- Cytogard is the newest addition to Gelman Sciences' laminar flow units. It has been designed to allow the safe handling of cytotoxic drugs. The cabinet, manufactured in compliance with Australian standard AS 2567 , the only legislative standard in the world for the handling of cytotoxic drugs, is also designed to satisfy British standard 5726 class II for containment. The construction cabinet has a stainless steel working area. It also includes a pre-filter and final high efficiency particulate air (HEPA) filter for maximum protection and a carbon absorption cell for handling volatile liquids.

Circle No.131 on Reader Service Card.

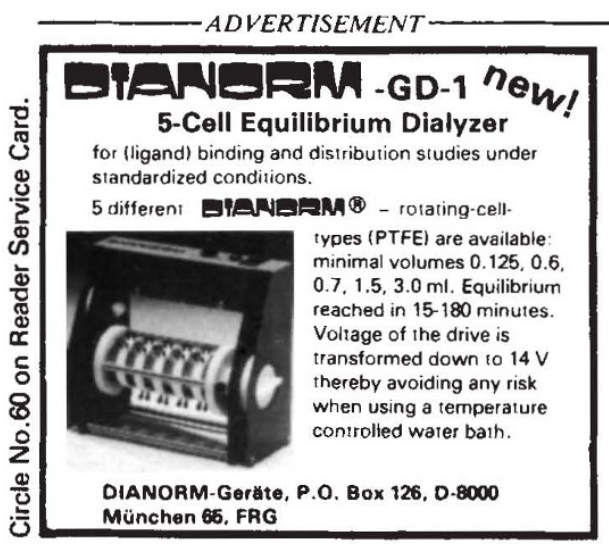

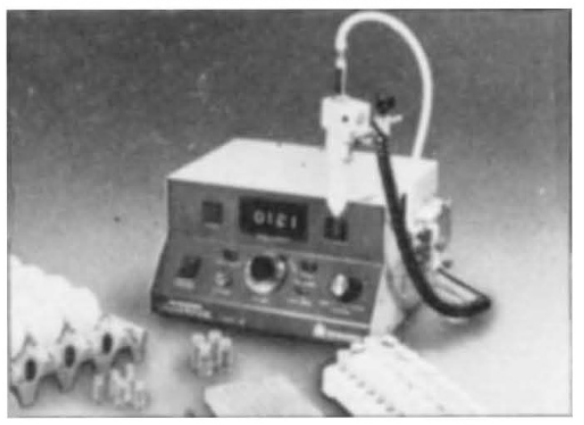

Wheaton's Unispense/Omni-Pette

- A new family of multi-function $p \mathrm{H}$ meters has been produced by Chemtrix. The model $410 p \mathrm{H}$ and $\mathrm{mV}$ meter is accurate to $\pm 0.1 p \mathrm{H}$ and $\pm 0.1 \% \mathrm{mV}$ units. When temperature is crucial, the model $420 \mathrm{pH} / \mathrm{mV}$ meter automatically compensates for sample temperature variations over the $0-100^{\circ} \mathrm{C}$ range. In addition to this the model $430 \mathrm{pH} / \mathrm{mV} /$ temperature meter measures temperature over the 50 to $200^{\circ} \mathrm{C}$ range with $\pm 0.5^{\circ} \mathrm{C}$ accuracy. All units have large LCD displays. They are battery powered and operate over the $0-14$ $p \mathrm{H}$ and $\pm 1,999 \mathrm{mV}$ ranges.

Circle No.132 on Reader Service Card.

- Brinkmann Instruments has released the Epson HX-20 system for Sartorius electronic balances. The system includes an Epson HX-20 computer; an interface for connection to Sartorius MP6, MP7 or MP8 electronic balances and standard programs for statistics, net weight or counting. The HX-20 computer is small enough to fit in a briefcase and requires no power cord. Circle No. 133 on Reader Service Card.
-Tissue-Tek III uni-cassettes, Tissue-Tek II cassettes and Tissue-Tek embedding rings are now available from Miles Scientific in a selection of colours. Uni-cassettes are available in five new colours: tan, lilac, orange, gold and aqua, in addition to the original five colours: white, pink, green, blue and yellow. The Uni-cassette system also includes a biopsy cassette for small specimens, which is grey. Mega-cassette is available for larger tissue specimens. Tissue-Tek II cassettes are also available in the same 10 basic colours as Uni-cassettes but there is also a clear, polypropylene cassette that allows embedded tissue to be seen. Tissue-Tek embedding rings are available in colours for the first time, these being white, pink, blue, green and yellow. The rings allow larger specimens to be embedded than does Mega-Cassette.

\section{Circle No.134 on Reader Service Card.}

- Futura II star-series refillable combination electrodes from Beckman are designed to measure $p \mathrm{H}$ in difficult situations. These include those in which ionic strength is low, such as in acid rain and drinking water, those where temperature varies substantially or in samples which are sensitive to silver. Star-series electrodes operate in the range of $p \mathrm{H} 0$ to 14 and are accurate to $\pm 0.01 \mathrm{pH}$. Response time in the $p \mathrm{H} 4$ to 7 range at constant temperature is stable to $\pm 0.02 p \mathrm{H}$ in $30 \mathrm{~s}$. For temperature changes from $25^{\circ} \mathrm{C}$ to $75^{\circ} \mathrm{C}$ in $p \mathrm{H} 4$ buffer, response is stable to $\pm 0.02 \mathrm{pH}$ in $30 \mathrm{~s}$. Slope is 97 to $100 \%$, temperature range is 5 to $100^{\circ} \mathrm{C}$ and isothermal point is $7 p \mathrm{H}$.

Circle No. 135 on Reader Service Card.

\section{Literature and assay kits}

- A new test for serum creatinine is now available from J.T. Baker Chemicals. In cooperation with Dutch clinical laboratories, J.T. Baker has developed a creatinine test based on the Jaffé method but free from bilirubin interference. Bilirubin, by use of a special reagent, is oxidized before the reaction rate is measured. The test has been designed for the kinetic measurement of creatinine. Application sheets currently available include Cobas Bio, RA-1000, PA-800 and manual techniques.

Circle No.136 on Reader Service Card.

- Boehringer Mannheim Biochemicals now offers an in vitro immuno-turbidimetric test kit for the determination of fibronectin levels in human plasma. The turbidity, which results from the antigenantibody reaction, is measured with a spectrophotometer. The assay uses a standard curve obtained from the set of standards included in the kit. Sample values are compared to this and the plasma fibronectin levels are then determined. The shelf life has been extended and the kit may now be stored at $4^{\circ} \mathrm{C}$.

Circle No.137 on Reader Service Card.
- A new ${ }^{3}$ H RIA kit is now available from Seragen for specific measurement of prostaglandin $\mathrm{E}_{1}\left(\mathrm{PGE}_{1}\right)$. This 100 -tube kit contains all the necessary reagents for the test, including antisera specific for $\mathrm{PGE}_{1}$ which show $9 \%$ cross-reaction with $\mathrm{PGE}_{2}$. Seragen's new $\mathrm{PGE}_{1}$ assay is sensitive to $20 \mathrm{pg}$ per $0.1 \mathrm{ml}$.

Circle No. 138 on Reader Service Card.

- An instructional brochure is now available from Tago that describes the structure and function of plasma lipoproteins in the transport of cholesterol and triglycerides. Other topics covered in the brochure include the clinical significance of apolipoprotein measurements, Tago's immunoassay systems and population studies using Tago's Diffu-Gen kits. Circle No. 139 on Reader Service Card.

- A new brochure is available from Boehringer Mannheim Biochemicals. The brochure contains a complete listing of all molecular biology products, including modifying enzymes, restriction enzymes, linkers and primers, inhibitors, nucleotides and nucleosides.

Circle No. 140 on Reader Service Card. 